\title{
Transport Cost Analysis of City Bus and Private Car Usage in Johor Bahru, Malaysia
}

\author{
Anil Minhans ${ }^{\mathrm{a}^{*}}$, Ali Moghaddasi ${ }^{\mathrm{b}}$ \\ ${ }^{a}$ Senior Lecturer, Faculty of Civil Engineering, Universiti Teknologi Malaysia, 81310 UTM Johor Bahru, Johor, Malaysia \\ ${ }^{b}$ Postgraduate Student, Faculty of Civil Engineering, Universiti Teknologi Malaysia, 81310 UTM Johor Bahru, Johor, Malaysia \\ *Corresponding author: anilminhans@utm.my
}

\section{Article history}

Received :10 May 2013

Received in revised form :

25 September 2013

Accepted :15 October 2013

Graphical abstract

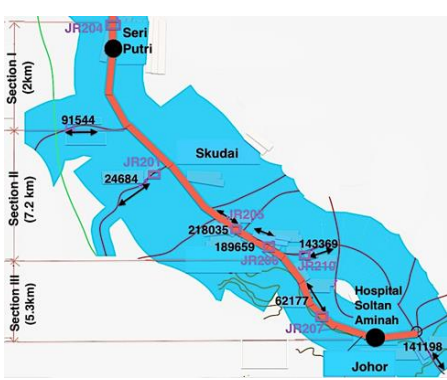

\section{Abstract}

Researchers worldwide are engaged in the evaluation of the performance of urban travel modes. Economic cost comparison studies are commonly used as instruments to substantiate the most favored mode in urban transport. This paper attempts to provide a comparison of current usage of city buses and cars in the Johor Bahru town of Malaysia. Technical costs, social costs and environmental costs are compared in ensuring accessibility and mobility on one hand and reducing accidents and environmental losses on the other. The study relates to a stretch of $14.5 \mathrm{~km}$ of 6-lane divided carriageway road connecting Pontian in the North and Johor Bahru, Malaysia, and Singapore in the South. Traffic data and Transport costs were obtained via primary and secondary sources. When car usage is involved, vehicle operating costs (VOC) was found to be three fold (RM 2.05/ person-km) than the VOC of bus usage (RM 0.7/ person-km). Similarly, social costs, which mainly included the cost of accidents, amounted to 80 times the accident cost associated with buses. Environmental costs were modeled based on speed and total vehicle volumes for $\mathrm{CO}$, NOx, SOx, and PM10 emissions and were expressed as total investment in pollution control. The environmental costs were then calculated in terms of medical costs believed to be caused by the pollution. These pollution costs amounted to 15 times the pollution cost associated with buses. The total transport costs were then obtained to provide comparative evaluation of the study modes. Furthermore, multiple future scenarios were created to provide cost analyses over time periods and modal split cases. In this regard, this paper provided a framework for a cost evaluation approach for an urban area. Results indicated that city buses are more costeffective than cars, assuming equality in the number of passengers.

Keywords: Vehicle operating cost; value of time; pollution cost; accident cost; environmental cost (C) 2013 Penerbit UTM Press. All rights reserved.

\subsection{INTRODUCTION}

High Car ownership is increasingly becoming a trend in Malaysian urban agglomerations. This is mainly triggered by high subsidies for car travel, low patronization of public transport and the affordability of Malaysian nationals to own a car. In recent years, it is common to find more than a car in high as well as in some middle income households. Besides, Malaysian road tax, registration fee, and vehicle annual insurance is one of the lowest in the ASEAN countries (Malaysia Automotive Institute, 2010) (Table-1). Moreover, Malaysian federal and state governments compensate for the gap in public transport services by providing fuel subsidies for car travel, which make car travel in economic terms, the second lowest among the ASEAN countries. In the wake of a low priority given to the public transport, the traffic effects are bound to unfold as severe traffic congestion, air pollution \& high traffic accident rate as well as economic effects of increased total debt on households and Malaysian economy due to low premium car loans.

In the early 1960s, the rapid economic progress of Malaysia has failed to identify public transport as a priority sector. As a result public transport service still lags behind in extent as well as in quality terms when compared to the ASEAN counterparts such as Singapore as well as Hong Kong and Japan. Many research studies document poor patronage of public transport modes as a result of deficiencies in the following: spatial and temporal availability, feeder connections to origin and destinations, reliability to schedule, traffic information, and the brand image. Malaysian Government in its ambitious National Transportation Program (NTP) has set a modal split of 50:50 between the public transport and individual motorized transport by the year 2020. As per the indices reported in Comprehensive Development Plan for the South Johor Economic Region, 2006, this modal split for Johor State is 70:30 between public and private transport modes. If the current trend continues, the increase in the private traffic share may cause massive congestion especially in and around the city centers of Malaysia. The travel time and its equivalent costs in private modes are bound to increase due to congestion and its delay effects. This is already viewed as the wasted time when value of time (VOT) of car travelers is considered. Furthermore, the quality of air would deteriorate due to high emissions of greenhouse gases (GHG). Even worse, the accident rates will rapidly increase with the increase in 
the private transport modes. Economic evaluation of the travel with public and private transport modes in Malaysia can therefore signify the necessity of prioritization and cost reduction efforts. Such comparative economic studies can justify the efforts towards the development of the mode carrying the least total transport costs.

Road User Cost (RUC) of the travel includes vehicleoperation costs and delay costs resulting from any effect of congestion in the traffic flow. They are a function of travel time, distance, duration, frequency, scope, and characteristics of different modes; the volume and operating characteristics of the traffic affected; and the currency rates assigned to vehicle operations and delays. RUC has many cost components that include VOC like: fuel costs, tire and tube costs, spare parts, repair and maintenance costs, depreciation cost etc. It also includes Value of Time (VOT) for travelers during the trip and mostly includes in-vehicle time and out-vehicle time, usually referred to as lost time. Both the time components incur cost to the traveler when delays are accounted. Urban travel modes are constantly analyzed for their abilities to control accidents. Accident costs surge with the use of unsafe modes viz. motorcycles, cars, lorries etc., these costs can be judgmental to promote the use of the least accident prone modes. Assessment of accident costs has suggested various approaches, some of them are- gross output approach, net output approach, and life insurance approach. As per Central Roads Research Institute (India), 1982, the accident costs involve gross loss of future output, notional value of pain, grief and suffering, hospital costs, court costs and administrative expenses of Police, Insurance Companies, funeral expenses etc.

Table 1 Comparison of petrol prices*, annual road tax** and annual vehicle insurance*** (Prices in Malaysian Ringgit)

\begin{tabular}{|c|c|c|c|}
\hline $\begin{array}{l}\text { ASEAN member } \\
\text { countries }\end{array}$ & $\begin{array}{c}\text { RON 95 } \\
\text { Petrol Prices }\end{array}$ & $\begin{array}{c}\text { Annual Road } \\
\text { Tax }\end{array}$ & $\begin{array}{c}\text { Annual } \\
\text { Vehicle } \\
\text { Insurance }\end{array}$ \\
\hline Thailand & 3.80 & 459 & 6736 \\
\hline Indonesia & 3.35 & 1837 & 4593 \\
\hline Malaysia & 1.90 & 398 & 3062 \\
\hline Singapore & 5.10 & 2756 & 7960 \\
\hline Vietnam & 3.60 & 0 & 3062 \\
\hline Philippines & 3.20 & 306 & 2847 \\
\hline $\begin{array}{l}\text { * Petro } \\
* * A n n t \\
* * * A n r\end{array}$ & $\begin{array}{l}\text { rices indicated } \\
1 \text { Road Tax is ba } \\
\text { al Insurance is }\end{array}$ & $\begin{array}{l}\text { per litre } \\
\text { ed on average } 5 \\
\text { sed on average } 5\end{array}$ & $\begin{array}{l}\text { a period } \\
\text { ar period }\end{array}$ \\
\hline
\end{tabular}

Many of these external costs including air and noise pollution costs, have recently been recognized. Often these costs pose difficulties of assessment since they have no value in market. Some authors argue that these costs are external to the road users and are under-valued (Jakob, Craig et.al.2006). One of the methodologies used to assess the economic cost of pollution was based on cost related to prevention of death and illnesses due to pollution (Sarkar et.al. 2010). Some other studies have included costs of traffic control and management and pollution reduction efforts expressed in monetary units - to present pollution costs. The economic analyses of pollution costs include costs involved in the reduction of $\mathrm{CO}, \mathrm{NOx}, \mathrm{SOx}$, and particulate matter of varying sizes. Therefore, these air pollution (AP) costs can produce significant differences in the decisions to prioritize modes for urban travel which ensure high mobility, safety, economy yet environmentally unsuitable.

In economic analyses, the comparisons that are made entirely on quantitative elements of VOC and VOT are largely unrepresentative. Each mode presents its own cost-performance package, including its strengths to limit environmental damage and accidents. Formerly, economic analyses presenting lower transport costs based on VOC and VOT were central to the selection or patronization of modes. Such analyses overlooked the environmental cost of pollution and social costs of traffic accidents. TRRL's (UK) RTIM Model and World Bank's HDM Model suggest procedures to calculate the total transport costs of a Highway project. However, both models lack the inclusion of factors that account social and environmental costs. Road user costs studies provide only two cost components i.e. the VOC and delays costs expressed through the VOT. These direct costs are decisive in evaluating alternative modes of travel. Some newer models incorporate social costs of accidents when considering the price factor in the modal choice (Jakob, Craig et.al. 2006) (Litman, 2013). There are limited studies that include technical cost, social cost and environmental cost components as a single cost performance package, thereby, suggesting a need for comparative studies.

Based on the above arguments, the aim of this study is to present a transport cost analysis of city bus and private car usage for Johor Bahru town in Malaysia. To achieve this aim, the following objectives are underlined:

- To provide a comparison of technical costs, social costs and environmental costs involved in the usage of public bus and private car for base year 2013;

- To evaluate the total transport costs for the horizon year 2020;

- To draw comparisons between the two defined scenarios: Do-nothing scenario and 50/50 modal split scenario.

\subsection{METHODOLOGY}

The methodology of this study considers the cumulative costs borne by road users (as road user cost), by society (as social costs of accidents), and by natural environment (as environmental cost) in two modes of travel: private car and public bus. All three costs were expressed in per person- kilometer units. The methodology includes the following: (1) Estimation of base and horizon year traffic, (2) Estimation of technical costs, as a summation of VOC and VOT costs (3) Estimation of environmental costs, as a function of speed and traffic volume (4) Estimation of social costs, as costs of fatal road accidents and other additional costs (5) Composition of cost per person-km, (6) Conduct sensitivity analysis by assessing the cost effects in two scenarios: 70:30 private car and public bus modal share and 50:50 modal share. (7) Conclude costs savings accrued to savings in VOC, VOT, reduced air pollution and reduced accidents.

\subsection{Selection of a Study Area}

To draw comparative studies, a road stretch from Sri Putri to Hospital Sultana Aminah (HSA) in Johor Bahru was studied. The route length of $14.5 \mathrm{~km}$ comprised of 6 lane divided carriage with 3 lanes in each direction. As per the Department of Public Works (JKR, Malaysia), Road type is JR205 is a federal road with many entry and exit points along the route. This site was selected, firstly, 
due to high prevalence of both public bus and private car and secondly, its being an arterial road with multiple connections to the expressway and collectors, for large traffic volumes were necessary to draw sharp comparison between two travel modes. Finally, as a main arterial road the possibility of data availability and collection were deemed high. Figure 1 exhibits a geographical account of the stretch selected for this study.

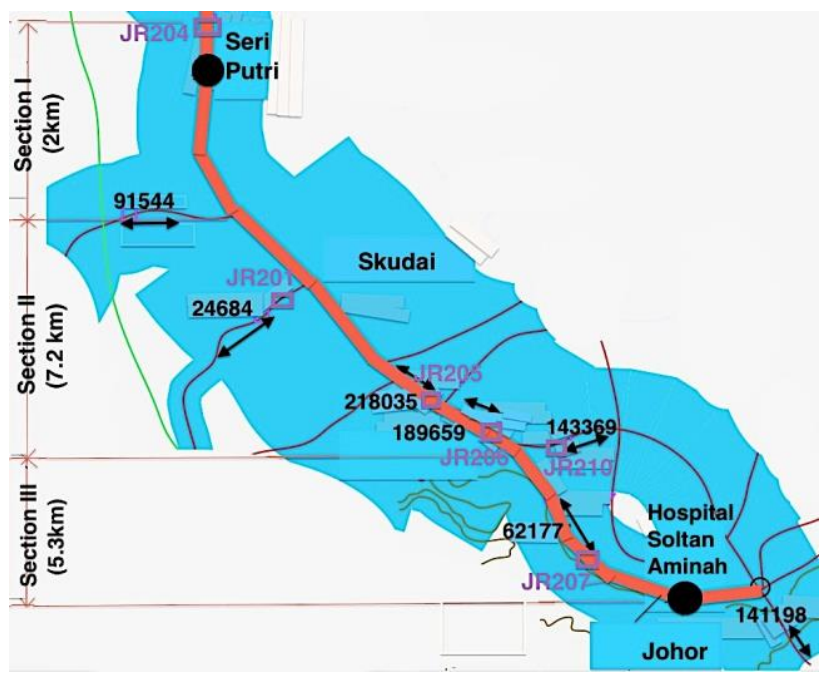

Figure 1 Study network

\subsection{DATA COLLECTION}

Data were collected from primary and secondary sources. The vehicle-operation costs were based on Malaysian fuel prices and assumed standard Malaysian tire costs, maintenance costs, monthly installment, interest costs etc. (Table 2). For instance, tire lifespan in Malaysia according to manufacturing companies was assumed to be $100,000 \mathrm{~km}$ (under average wet/dry weather conditions). Thus, cost of tire per kilometer was determined accordingly; also fuel mileage calculation was based on the consumption of 1 liter petrol/diesel for 13 kilometers for cars. Installment for private cars was considered at an average rate of $850 \mathrm{RM} /$ month, but for public buses there were no installments. Private car depreciation costs were ascertained at $50 \%$ cost after 3 years; similarly, public buses depreciation cost was calculated at $40 \%$ that of a new bus cost, after 10 years usage (National Automotive Policy). Average travel for a car in a year was assumed to be $30000 \mathrm{~km}$.

The VOT costs were based on the wage-rate method. In this method, the average earnings of travelers in different categories of modes are considered. Data related to purpose of travel, occupation, car ownership, monthly income and origin-destination were collected by interviewing travelers. The travelers were classified into 3 income groups, namely low-income group (LIG), middle income (MIG) and high-income group (HIG). Time components such as access time, waiting time, online travel time, delay time, boarding and alighting time, and departure time were calculated in arriving at the bus travel time. The average coverage of public buses - station to residential area - was assumed to be 300 meters. The half of the time that a person waits for bus was counted as waiting time. The study network from Hospital Sultanah Aminah to Seri Putri had 12 bus stations witha total of 249 seconds alighting/boarding time. The VOT equivalent costs were based on average wage rate, considering 24 working days and 8 working hours. Occupancies were assumed to be 2 and 35 persons in private car and public buses, respectively. The income data and car ownership were used to define modal split between public and private transport use for a given origin and destination pair.

Road traffic volume data for the study network was obtained from 6 chainage points (JR 201, JR 204, JR 205, JR 206, JR 207 and JR 210) of RTVM Report, Department of Public Works for the year 2009, 2010, 2011 and 2012. Historic traffic volumes for 10 years were utilized to provide growth rates in RTVM traffic reports. Same traffic growth rates were adopted to forecast traffic for base year 2013 and horizon year 2020. The pollution emission factors were based on the EMFAC Model issued by the California Air Resources Board and on California Transportation (CalTrans) estimates (Environmental Protection Agency, 2011). These have been calibrated at Malaysian 2013 price indices. Average journey speed of private car was obtained by conducting traffic speed studies for three runs of test vehicle on $29 \mathrm{~km}$ (two-way) study network. Similar speed and delay surveys were conducted for bus mode to find the distribution of time a bus spends in travel into 3 categories, particularly, the running time, dwell time and other categories of delay time. The average journey speed of bus was based on all above three components of time for three runs.

All accident data were taken from Tun Aminah Police station in Johor Bahru. Accidents were categorized into fatal accidents, major accidents, minor accidents and damage accidents. Accident data were also obtained separately for both the transport modes. The cost of accidents in all categories was obtained from Malaysian Institute of Road Safety (MIROS). The total cost of accident comprises of monetary value of gross loss of future output, notional value of pain, grief and suffering, hospital expenditure, court expenditure, expense of police, insurance companies etc.

\subsection{ANALYSIS}

4.1 Estimation of Base Year 2013 and Horizon Year 2020 Traffic

RTVM 2009, 2010, and 2011 were used to forecast traffic volume for the study network base year 2013, and for horizon 2020. Traffic volume data for 2009 were shown in Figure 1 of the study network (RTVM 2009). For the purpose of the study, the study network was divided into three sections of $5.3 \mathrm{~km}, 7.2 \mathrm{~km}$ and $2 \mathrm{~km}$ for detailed analysis of traffic volume. For each section normal growth rate for the last 10 years was used to determine the traffic volume and modal split for the projected years. Car, taxies and motorcycles were categorized as private transport modes and public buses were categorized as public transport mode. Traffic volume was converted to pcu/hr. For the year 2020, two scenarios were considered, do-nothing-case; where current level of modal split are adopted and 50:50 case, where equal modal split are considered. As indicated earlier, the second case forms a part of the policy listed in the Comprehensive Development Plan for the South Johor Economic Region with a vision to strengthen public transport modes.

\subsection{Estimation of Technical Costs}

Technical Costs included two costs: vehicle operation costs (VOC), and time costs of travelers based on their value-of-time (VOT). The total costs of vehicle operation were calculated per person kilometers (Table 2).

Value of Time (VOT) was calculated by level of income group of each household. A comprehensive survey was conducted to find out three level of income group: Low-income group (LIG), Medium-income group (MIG), and High-income group (HIG). Based on the responses and wage-rate method, the data for value of time for the studied section journey were obtained (Table 3). 
Assumption of average coverage of bus stations to residential area being 300 meters, similar assumptions were deduced from it, such as access and egress time from the bus stop as well as waiting time at the bus stops. Total travel time by public buses and private cars were calculated 79.3 and 23 minutes respectively. This provided basis of calculation of value of time of travelers in both modes.

For instance, the VOT cost of journey for a LIG group per person per study network was RM 5.4. The total cost of journey by bus and car for all income groups for the study stretch were RM12.6 and RM 22.7 respectively.

Table 2 Comparison of VOC between public and private transport modes

\begin{tabular}{|c|c|c|c|}
\hline & $\begin{array}{c}\text { Cost Indicators } \\
\text { (Person-km) }\end{array}$ & $\begin{array}{c}\text { Car } \\
\text { (Person-km) }\end{array}$ & $\begin{array}{c}\text { Bus } \\
\text { (Person-km) }\end{array}$ \\
\hline \multirow{9}{*}{ VOC } & Fuel Cost & 0.075 & 0.0004 \\
\hline & Tires Cost & 0.004 & 0.0001 \\
\hline & Repair and Maintenance Cost & 0.100 & 0.0458 \\
\hline & Monthly Installment & 0.250 & 0.0000 \\
\hline & Interest & 0.000 & 0.1600 \\
\hline & Road Tax and Insurance & 0.103 & 0.0023 \\
\hline & Driver Salary & .000 & 0.1800 \\
\hline & Depreciation Cost & 1.520 & 0.3200 \\
\hline & Sum & 2.05 & 0.71 \\
\hline
\end{tabular}

Table 3 VOT and public/private transport usage

\begin{tabular}{|c|c|c|c|c|c|c|}
\hline \multirow[t]{2}{*}{$\begin{array}{l}\text { Income } \\
\text { Ranges }\end{array}$} & \multirow[t]{2}{*}{$\begin{array}{c}\text { Monthly } \\
\text { Salary } \\
\text { (RM/month) }\end{array}$} & \multirow[t]{2}{*}{$\begin{array}{c}\text { VOT } \\
(\mathrm{RM} / \mathbf{h r})\end{array}$} & \multirow[t]{2}{*}{$\begin{array}{c}\text { Bus } \\
\text { Transport } \\
\text { Usage }(\%)\end{array}$} & \multirow[t]{2}{*}{$\begin{array}{c}\text { Car } \\
\text { Transport } \\
\text { Usage }(\%)\end{array}$} & \multicolumn{2}{|c|}{$\begin{array}{c}\text { VOT } \\
\text { / Study } \\
\text { Network } \\
\text { (RM) }\end{array}$} \\
\hline & & & & & Bus & Car \\
\hline $\begin{array}{l}\text { Low } \\
\text { Income } \\
\text { Group } \\
\text { (LIG) }\end{array}$ & $0-2000$ & 6.3 & 65 & 35 & 5.4 & 0.8 \\
\hline $\begin{array}{l}\text { Medium } \\
\text { Income } \\
\text { Group } \\
\text { (MIG) }\end{array}$ & $2000-5000$ & 21.9 & 23 & 77 & 6.7 & 6.5 \\
\hline $\begin{array}{c}\text { High } \\
\text { Income } \\
\text { Jroup (HIG }\end{array}$ & $>5000$ & 40.6 & 1 & 99 & 0.5 & 15.4 \\
\hline
\end{tabular}

Sum (VOT/ Study Network)

$12.6 \quad 22.7$

Sum (VOT/ km)

$0.9 \quad 1.6$

\subsection{Estimation of Environmental Costs}

Environmental costs were estimated from air pollution. Noise pollution, vibrations and other negative effects were not considered. Emissions included those emitted directly into the atmosphere, such as carbon monoxide (CO), particulate matter (PM10), oxides of nitrogen (NOX), and oxides of sulfur (SOX). Based on traffic volume in projected years, the amounts of pollutants were calculated. An air pollution model was based on vehicle speed named as EMFAC; developed by the California Air Resource Board (CARB), this model was used to determine the selected levels of pollutants. This model determined the pollution emitted (ton) into the atmosphere. The cost of pollution was based on the Caltrans estimates ( $\$ /$ U.S. ton) of health cost of transportation emissions in 2010 rates, however, these estimates have been calibrated for Malaysian price indices for the base year 2013.

Emissions Cost

$=\sum$ (veh— $\mathrm{km} \times$ Emission Rate $\mathrm{x}$ Costs per ton)

by Emissions Type (e.g. CO, NOx, Sox and PM)

Table 4 demonstrates the amount of pollution produced by each mode for the average journey speeds among the two modes. Table 5 shows the health cost per ton for different pollutants. The highlighted row indicates the values used in this study.

Table 4 EMFAC emissions factors (g/mi)- Cal-B/C program

\begin{tabular}{cccccccccccc}
\hline \multirow{2}{*}{ Speed } & \multicolumn{4}{c}{ Cars } & \multirow{2}{*}{ Speed } & \multicolumn{5}{c}{ Buses } \\
\cline { 2 - 7 } & CO & NO & PM10 & SO $\mathbf{x}$ & & & CO & NO x PM10 & SO x \\
\hline 40 & 8.02 & 0.81 & 0.03 & 0 & 40 & 11.27 & 10.18 & 0.25 & 0.11 \\
\hline 45 & 7.77 & 0.81 & 0.03 & 0 & 45 & 11 & 10.59 & 0.23 & 0.11 \\
\hline 50 & 7.66 & 0.82 & 0.03 & 0 & 50 & 10.98 & 11.35 & 0.22 & 0.11 \\
\hline $\mathbf{5 1 . 2}$ & $\mathbf{7 . 6 8}$ & $\mathbf{0 . 8 2}$ & $\mathbf{0 . 0 3}$ & $\mathbf{0}$ & $\mathbf{5 1 . 2}$ & $\mathbf{1 0 . 9 9}$ & $\mathbf{1 1 . 7 5}$ & $\mathbf{0 . 2 2}$ & $\mathbf{0 . 1 1}$ \\
\hline 55 & 7.71 & 0.84 & 0.03 & 0 & 55 & 11.19 & 12.54 & 0.21 & 0.11 \\
\hline 60 & 7.97 & 0.88 & 0.03 & 0 & 60 & 11.69 & 14.3 & 0.2 & 0.11
\end{tabular}

Table 5 Health cost of transport emissions in 2010 rates

\begin{tabular}{ccc}
\hline Pollutant & Urban Area & Rural Area \\
\hline Carbon Monoxide & 70 & 65 \\
\hline $\begin{array}{c}\text { Nitrogen Oxide (NOx) } \\
\text { Particular Matter } \\
\text { (PM10) }\end{array}$ & 16,300 & 12,100 \\
\hline $\begin{array}{c}\text { Sulfur Oxide (SOx) } \\
\text { Volatile Organic } \\
\text { Compounds }\end{array}$ & 65,800 & 94,000 \\
\hline
\end{tabular}

\subsection{Estimation of Social Costs}

Social costs were based on accident costs, which were categorized as: Fatal, Major, Minor, and Damage Accidents. Accident statistics often are reported in terms of accident rate and accident frequency. Accident rate is the number of accidents expected or observed along a roadway segment during a time period normalized to the roadway segment length and the traffic volume over the same period. Accident rate typically is expressed as accidents per vehicle-miles or vehicle-km (in SI units) T or accidents per million vehicle travelled. The model used for calculating the crash rate for a given network is presented (1). The duration of analysis period is 
assumed 7 years, the length of the segment was $14.5 \mathrm{~km}$, AADT was obtained from RTVM, and also, total accidents were obtained from police accident reports. The following model is applied:

Accident Rate $(A R)$

$=\frac{A * 10^{6}}{T * L * A A D T * 365}$

where,

$\mathrm{AR}=$ number of accidents per million vehicle-miles/kilometers of travel per length of segment, and per annual average traffic (in both directions), the SI units were used for Malaysian case.

$\mathrm{A}=$ average number of accident along the roadway segment for the analysis period

$\mathrm{T}=$ duration of the analysis period (years)

$\mathrm{L}=$ length of roadway segment (miles)

AADT $=$ annual average daily traffic (in both directions)

\subsection{CONCLUSIONS}

\subsection{Traffic Projection for Horizon Year 2020}

Figure 2 presents the traffic volume estimates for the base year 2013 and two prospective scenarios for the horizon year 2020. Comparison of the base year 2013 estimates with the year 2020 (donothing-case) reveals that the number of private vehicles (Cars, Motorcycles and Taxis) will become almost 15 times the number of public vehicles (Buses). According to modal split 50:50 case, the numbers of private vehicles will become 6 times the number of the public vehicles. Finally, cost of all of indicators: VOC, VOT, air pollution costs, and accident costs were calculated per kilometer for 2013, and 2020 (do-nothing-case and 50\%- 50\% share) to compare and evaluate the total transport costs in projected years.

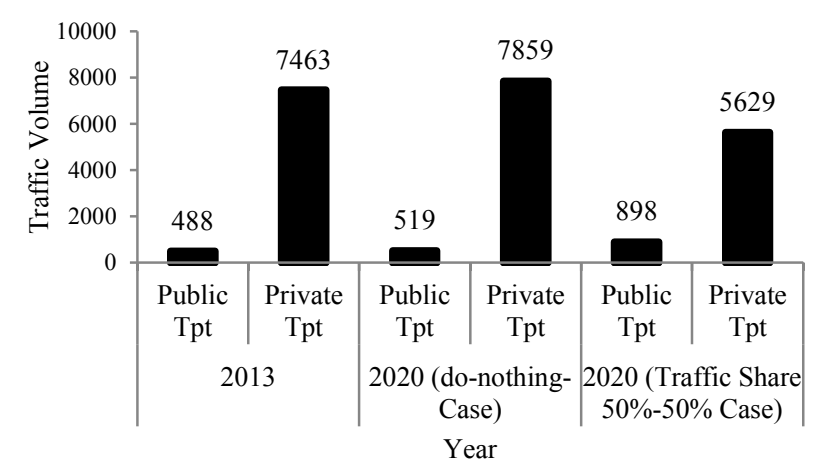

Figure 2 Traffic volumes by public and private for projected years

Although the Malaysian government subsidizes the use of private transport through fuel subsidies and low loan repayments, the VOC for private transport was observed almost 3 times the VOC for public transport. In addition, the VOT of private transport user was found 1.7 times the VOT for public transport user.

Effect on the environment were studied under two scenarios, current level of modal split (70:30) and future levels of modal split (50:50) were compared. The $20 \%$ increase in ridership is anticipated in the 50:50 modal split case. According to Figure 3, for the base year 2013, the private mode pollution contribution was found to be 14 times that of public mode. However, for the 50:50 modal split case, it is estimated to be 6 times that of public mode, which indicates that development of public mode will contribute to a better air quality in 2020 . A $28 \%$ reduction in air pollution and its related costs was estimated after implementing the development plan for South Johor Economic Region in 2020 (Figure 4).

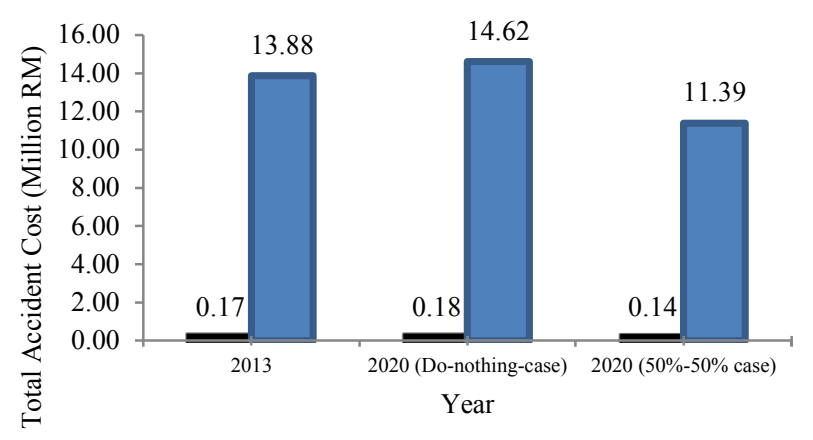

Public Tpt DPrivate Tpt

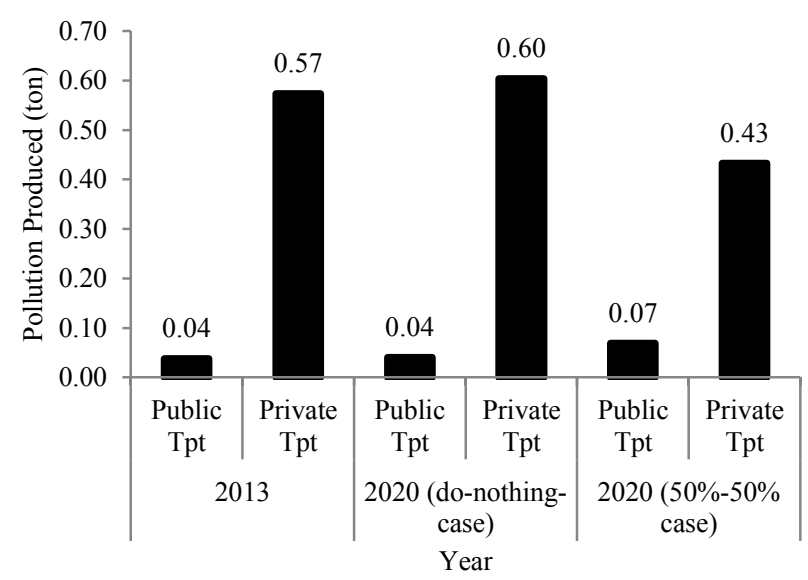

Figure 3 Total pollution produced (ton)

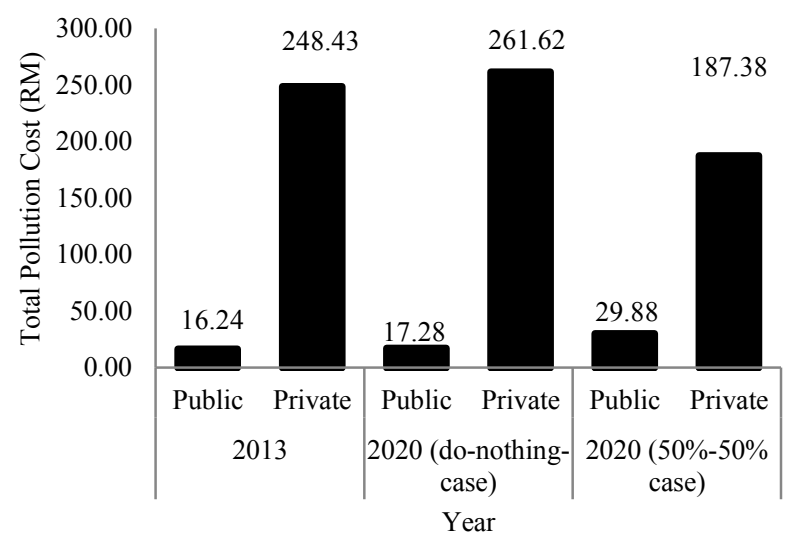

Figure 4 Total pollution costs (RM)

Accident analyses associated eighty percent accidents with the private mode (cars, motorcycle and taxis) and only $1 \%$ of total accidents with the public mode (Figure 5). There was no significant difference in the accident share among the public transport modes, however, among the private modes, it increased to $5 \%$ in donothing case, and conversely, it decreased to $18 \%$ in 50:50 modal split case. 


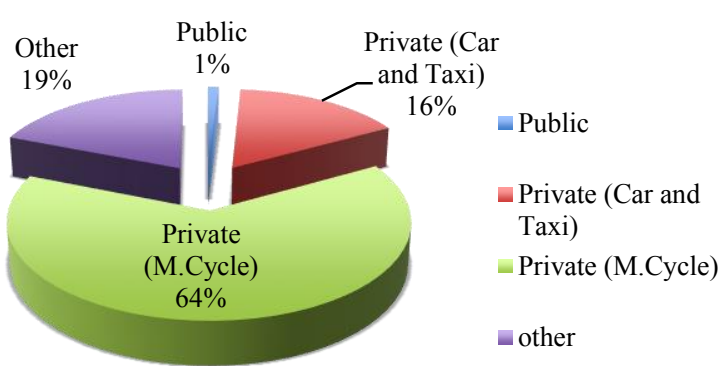

Figure 5 Accident share by modes

Due to high fatal accident costs in Malaysia, the accidents are central to the surge in total transport costs. In fact, every fatal accident costs RM 1.2 million to the society. There is a high contribution of motorcycles in accidents, as much as $64 \%$ of total accidents and $80 \%$ of fatal accidents. Figure 6 indicates that accident costs involving private modes were found to be 80 times more than that in public modes for base year as well as horizon year 2020 .

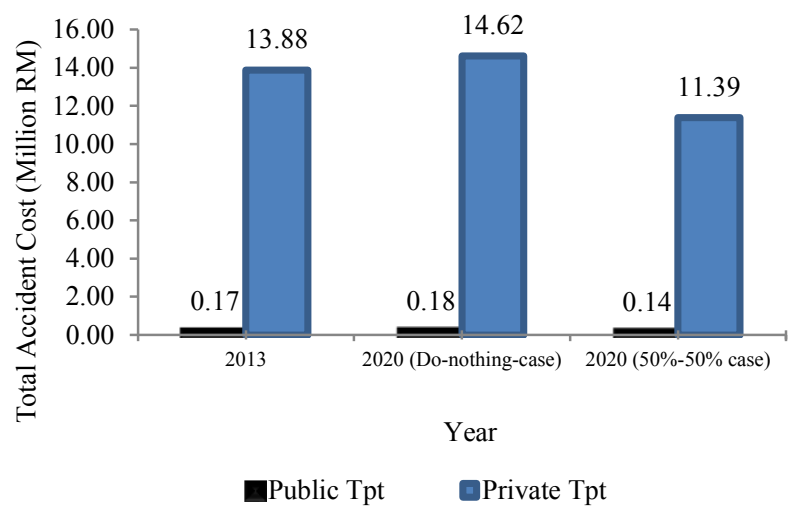

Figure 6 Total accident costs (Million RM)

\subsection{DISCUSSION}

Total transport costs involved the individual estimation of the technical, social, and environmental costs of this study network (Figure 7-8). These were analyzed for two types, first with accident cost and second, without the accidents costs. Figure 7 shows all indicators without accident costs. After considering the scenario associated with the implementation of Comprehensive Development Plan for South Johor Economic Region, air pollution revealed a decrease of $28 \%$ compared to do-nothing case, while the VOT and VOC remained same.

Fatality accident increased the total cost of accidents by six times. Surveys have shown a high prevalence of motorcycle use among the members of the low-income group (LIG). Equally, the use of public modes is predominant among the Low income group. Thus, Development Plan for South Johor Economic Region reveals a major influence in decreasing the number of accidents, especially fatal accidents.

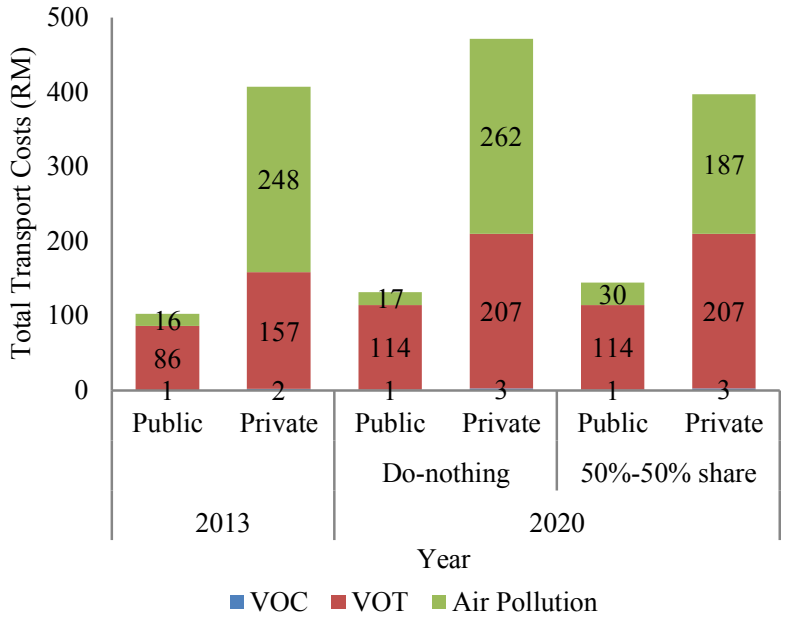

Figure 7 Total transport costs without accident costs

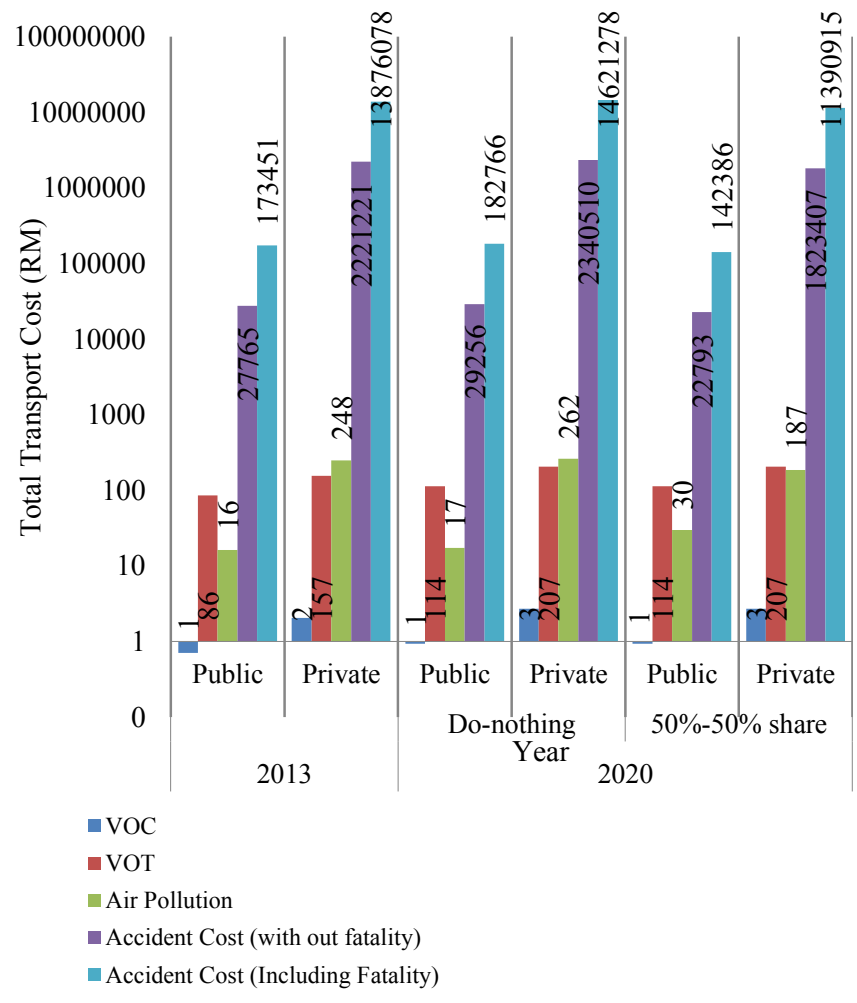

Figure 8 Total transport costs including accident costs

\subsection{CONCLUSION}

Analyzing transport costs are not only limited to VOC and VOT, pollution and accidents costs as given in the paper. These are instruments to justify the selection of prioritization of transport modes in an urban conglomeration. Thus, evaluation and comparison of the total transport cost would require multiple and detailed indicators to cause sharp variations in the selection as well as prioritization of different modes of transport. This paper has documented the results based on the total costs with limited indicators: Road User Costs (RUC), Environmental costs and Social costs. We have demonstrated that the cumulative cost can be viewed as a Cost Performance Package. In this attempt, the paper has presented a framework for estimating and comparing different 
costs that are involved in public and private travel. The decision making, based on these costs, can be further refined by choosing multiple networks, multiple modes, and multiple indicators. In this context, the study, although, was confined to given network characteristics only and was not totally representative for all Malaysian conditions, but provides some new insights in the area of transport cost analysis. Similar studies, however, by expanding the domain of predictor variables can be conducted to provide a better assessment mechanism for comparison between modes. Future researcher might also include direct and indirect costs of transport, for further analyses.

\section{Acknowledgement}

The Author (Principal Investigator) does hereby acknowledge Ministry of Higher Education (MOHE) and Universiti Teknologi Malaysia (UTM) for providing funding for this research (Vote Number 07J06) and Research Management Center (RMC) for logistical assistance provided throughout the course of this project.

\section{References}

[1] A. Jakob, J. L. Craig, G. Fisher. 2006. Journal of Environmental Science \& Policy 9. Transport Cost Analysis: A Case Study of the Total Costs of Private And Public Transport in Auckland. 55-66.

[2] A. M. Levinson, David, G. 1998. J. Transportation Research: D. The Full Cost of Intercity Highway Transportation. Pergamon. 3(4).

[3] C. Wilkie. 2010. The Benefits of Public Transport. Paper Presented at the Tourism \&Transport Forum. Australia.

[4] Central Road Research Institute (CRRI). 1982. Road User Cost Study. Final Report. New Delhi.

[5] COTPA. 2009. Benefits of Public Transport. Retrieved 22 May 2012, 2012, from http://www.gometro.org/benefits.

[6] COTPA.2009. Benefits of Public Transport Retrieved 22 May 2012, 2012, from http://www.gometro.org/benefits.

[7] D. W. Borchardt et al. 2009. Capacity And Road User Cost Analysis. Texas Department of Transportation and the Federal Highway Administration.
[8] David Meunier, Emile Quinet. 2012. Journal of Research in Transportation Economics. Applications of Transport Economics and Imperfect Competition. 36.

[9] Environmental Protection Agency (EPA). 2013. Official Release of EMFAC2011 Motor Vehicle Emission Factor Model for Use in the State of California. Federal Register. 78(44).

[10] Environmental Resources Management Australia. 2008. www.erm.com Report No.001483.

[11] J. J. Laird, J. Nellthorp, P. J. Mackie. 2005. Journal of Transport Policy 12. Network Effects and Total Economic Impact in Transport Appraisal. 537-544

[12] J. Mallela, S. Sadasivam. 2011. Work Zone Road User Costs: Concepts and Applications, U.S. Department of Transportation Federal Highway Administration. Washington DC.

[13] Litman, T. 2006. Evaluating Public Transit Benefits and Costs: Best Practices Guidebook. Victoria Transport Policy Institute.

[14] Malaysian Automotive Institute (MAI). 2011. Annual Report Global Automative Trends and Challenges. Strategic Research Publication.

[15] Malaysian institute of Road and Safety Research (MIROS). 2013 General Road Accident Data in Malaysia, available at: http://www.miros.gov.my.

[16] Malaysian Institute of Road Safety Research (MIROS). 2012. Review Of The National Automotive Policy On Car Maintenance Issues: Malaysia's Automotive Ecosystem Explained.

[17] P. K. Sarkar, V. Maitri. 2010. Theory and Applications of Economics in Highway and Transport Planning. New Delhi: Standard Publishers Distributors.

[18] PTV. 2012. Benefits of Public Transport Retrieved 22 May 2012 2012, from http://ptv.vic.gov.au/about-metlink/benefits-of-publictransport/.

[19] S.Grant-Muller, J. Laird. 2007. International Literature Review of the Costs of Road Traffic Congestion. Scottish Executive. Available at (www.scotland.gov.uk).

[20] Silvia Banfi. et al. 2000. External Costs of Transport; Accident, Environmental and Congestion Costs in Western Europe. Available at: www.infras.ch and www.iww.uni-karlsruhe.de.

[21] T. Litman. 2002. Evaluating Public Transit's Benefits and Costs. Victoria Transport Policy Institute.

[22] T. Litman. 2013. Smart Congestion Relief: Comprehensive Analysis Of Traffic Congestion Costs and Congestion Reduction Benefits. Victoria Transport Policy Institute

[23] TCRP Report 28. 2002. Estimating the Benefits and Costs of Public Transit Projects. National Academy Press. Washington.D.C.

[24] Traffic and Transportation Planning. 2010. Central Road Research Institute of India. Annual Report. 